\title{
CORPORAL PRACTICES AND HEALTH PROMOTION
}

\author{
Sylvie Fortin \\ $\mathrm{PhD}$. \\ University of Québec à Montréal \\ E-mail: fortin.sylvie@uqam.ca
}

The paper analyzes the relations between corporal practices and health promotion, examining examples coming from the Dance Field. In a societal context in which body receives more and more attention, it is important that professionals in the field of art, physiotherapy, and physical education engage in critical reflexivity about values entangled in mainstream and alternative discourses.

Keywords

Dance. Corporal Practices. Health Promotion. Body Discourses.
O artigo busca refletir sobre as relações entre práticas corporais e promoção da saúde, analisando exemplos oriundos do campo da dança. Em um contexto social em que o corpo recebe cada vez mais atenção, se faz importante que os profissionais da arte, fisioterapia e educação física reflitam de forma crítica sobre os valores entranhados tanto nas correntes dominantes como em discursos alternativos.

Palavras-chave

Dança. Práticas Corporais. Promoção da Saúde. Discursos do corpo. 
In Western societies people are increasingly encouraged to participate in sport and physical activities because of the perceived benefits to their health and wellbeing. Dance, physical education and sport are often seen as key sites through which an active lifestyle can be established, and a place where people can learn about their body and their psychological and physical health. Obviously, these environments are not neutral. They convey bodily norms as well as implicit and explicit norms about health. In this closing keynote for the School of Physical Education's 75 Year Commemoration Event, I will present questions and thoughts about corporeal practices and health in order to develop a collective critical reflective process about the role we can play as movement specialists in a societal context in which body receives more and more attention. I will do this from my standpoint of a dance and somatic practitioner and theorist in Canada, I hope that, despite a different cultural context, it will stimulate exchange among our group composed of students, physical education teachers, physiotherapists, artists, and researchers in the domain of sport, dance and moment in general. To do so, I will use some of the conclusions of my research investigating how professional dancers and dance students construct their health.

My motivation to study health in the milieu of professional dancers started early on in my career when I stopped dancing because of an injury. I then became more sensitive to this issue of dance injuries and health. Studies around the world show that between 70 to $80 \%$ of dancers suffer from injuries and that psychological issues are as important as well as physical and environmental factors. I was eager to implement changes toward safer dance prac- tice in my environment, but I faced the disinterest of many people because, physical injuries and psychological distress are seen as being part of the game: "This is the reality of the professional dance milieu", people would say, "It is the ways things are". In order to develop a health promotion program in my dance milieu, I realized that I needed to step backward and to understand how people think about health, and how dancers construct their health.

From 2002 to 2008, my research assistants and I conducted a series of studies with more than one hundred professional and pre-professional contemporary dancers, choreographers, rehearsal directors, and high school dance students in Montreal, Canada (Fortin, 2008). We conducted individual interviews and engaged in participant observations of dance classes, training and rehearsals, which provided us with rich, grounded material that we analyzed qualitatively. We are now up-dating parts of this research to deepen our understanding of how artists construct themselves and are constructed in many ways by various, and sometimes competing discourses, to use Foucault's term.

\section{Theoretical grounds}

According to Foucault (1963), discourses are composed of ideas, attitudes, beliefs, courses of actions and practices that enable, as much as they constrain, what can be said or done in particular times and places. In other words, discourses do not simply reflect social realities through language; they can better be understood as discursive and behavioral practices that shape social realities. For example, the dominant Western health discourse posits individuals as being primarily responsible for 
their own health, linking a range of bodily practices with the attainment of health. Present in this discourse are the injunctions to life-long consumptions of health practices, services and products. Drawing on Foucault's analysis of the panopticon prison, we can say that people adopt a self-imposed internalized form of bodily control according to these injunctions. Concretely, the dominant discourse implies constant surveillance and auto-surveillance, encouraging individuals to avoid risk and to adopt safe behaviors such as exercising and resting well, not smoking or eating junk food. Of course guilt has become intimately tied to an individual's failure to achieve it.

Recently, people turned to digital technologies to assist them in the development and maintenance of their health and body control with sometimes an obsessive "self-tracking" attitude, a term coined by Gary Wolf and Kevin Kelly. In 2007, they found a blog named "SelfQuantified"1 to refer to the collection and study of numbers since self-trackers log data about their life styles to better monitor their health. Health applications or apps for self-improvement are growing tremendously. According to Boxall (2014), there are 100,000 apps dedicated to mobile health. Apps seek to empower mundane users as more informed consumers, but sometimes they become an instrument of self-torture say critics. Indeed the path to self-improvement can be a challenging one. Some people quit tracking because of the strangling pressure it is exerting on them. "One pound heavier one morning? You're fat. Skipping a day of running or your daily dance class? Your lazy". Self-tracking devices has led to what Lupton (2014) called a "self-tracking

$1 \mathrm{http}: / / q u a n t i f i e d s e l f . c o m / a b o u t /$ culture" in which prevails the belief that data are superior form of knowledge to wok upon and improve the self. In the past, when people had problems they tended to favour talking cures, but the prevailing neoliberal discourse value self-responsibility operating thanks to the affordances of contemporary digital technologies.

She stresses that while goal setting can serve personal improvement, it also serves to enhance corporate profits in the exercise/health industries. Relying on your bodily sensations rather than on your intelligent watch is almost a sin committed toward your intelligent watch that knows how much running you have to do and how much rest you need. A long time ago, in 1987, Habermas argued that major corporations have come to replace religions, familial, and community institutions in the production of meaning, personal identity, values and knowledge. Such a powerful influence on society by corporate ideologies has been called the "colonisation of the life world" by Habermas. In the same line of ideas, Foucault talks about "the bio-politic" for the control, surveillance and regulation of bodily processes (2004). Geneviève Rail (2015) points out that Deborah Lupton (1995) wrote about the "health imperative" 20 years ago and that recently Cerderström and Spicer (2015) extended the concept to the larger domain of wellness. As Rail, I borrow from these authors to talk about the "health and wellbeing imperative" of the dominant discourses and its "self-tracking culture".

Fortunately, discourses are not stable and there are many, often contradictory, discourses that circulate at any given time. For example, we could say that yoga, meditation, and somatic education (sometimes located under the umbrella term of mindfulness practices) offer 
an alternative to the dominant health discourse. To some degree, the development of the mindfulness trend offers a marginal discourse since it promotes sensing and feeling as the basis of our thoughts and actions. Actually, I could argue that yoga, with its numerous derivative practices specialized for different body parts (abdo-yoga, butt-yoga, etc.) or functions (power yoga, restorative yoga, etc.) is moving toward the mainstream market of bodily practices and health. The well-being market is expanding tremendously and is part of an extremely lucrative market. For Foucault, the discourse that dominates at a specific time and place produces common sense knowledge for that time, which comes to be accepted to be true. Therefore, dominant discourses construct current truths and what power relations they carry with them for a particular time. This theoretical framework matched perfectly our data with professional, pre-professional dancers and high school dancers' students.

\section{A conflated no- tion of health}

Adopting a socio-constructivist epistemo$\operatorname{logy}^{2}$, our research on dancer's health is part of a growing body of literature on how diverse cultural groups construct their health differently. Despite the definition of health provided by the World Health Organisation, each subcultural group has its own definition of health. For example, for a group of Korean students in Canada, health consisted in being able to go through their university years while sustai-

$2 \mathrm{~A}$ a socio-constructivist epistemology posits that our reality is constructed out of our personal experiences, values and ways of being emerging from our social interactions in the world. It emphasizes the individual construction of the world and the shared discourse with society (McCarty \& Schwandt, 2000). ning the enormous pressure for success put on them by their parents. In another example, a group of elderly Portuguese women in Montreal saw health as being able to take care of their garden in the summer after the winter has forced them to reduce their physical activities (Rail et al., 2002).

The results of our studies that looked at high school dancers' discursive constructions of health corroborate the findings of a large similar research in physical education conducted by Margaret MacNeil and Geneviève Rail (2010). The authors explain that for Canadian youths health meant having a particular body shape and weight and, more specifically, being not too fat, overweight or obese. The narratives were highly gendered. In general, the young men alluded to health and the "normal" body as not fat, muscular and well-shaped. For the young women, being slim and toned (but not too much) corresponded to a female's proper body shape. The notion of health was conflated with physical appearance and weight. In Rail's studies in physical education, as well as in our studies in dance, it seemed as though the young people's concern was more about "looking good" or "not being fat" than about "being healthy." Therefore, we concluded that the high school dance students' constructions of health were very much tied up with the larger dominant social discourses and health imperative.

In the same vein, our study with contemporary dancers tended to align themselves with the dominant discourse of Western theatrical dance that promotes an ideal body where aesthetic criteria of beauty, slimness, virtuosity, and devotion prevail, and where fatigue, pain and injury are accepted silently (Laws, 2005; Sorignet, 2010). When questioned about the 
relationship between health and dance, the artists in our study relegated the former to a backstage role, valuing pushing the limits of the art form and expanding individual skills sometimes beyond reasonable limits. The artists we interviewed regarded dance as a "risky endeavour", since dance-making involves "seeking innovation", and this invariably "damages the body".

The dominant discourse of Western theatrical dance is a powerful force, not only for professional artists, but also for the large public. When looking at TV programs such as "So you think you can dance" or "Dancing with the stars", we see a clear colonization of the body. ${ }^{3}$ Health is a very personal issue but it is also an extremely political one. Popular media are obsessed with attracting youth with dreams of glory. Photoshop is 25 years old. Digitally altered images of bodies to make people look thinner or younger is part of our daily life. Popular media and Western theatrical dance converge to shape bodies in a very specific way with expansive costumes and make up. The success of the dance competitions "So you think you can dance" and "Dancing with the stars is tremendous all over the world. The former is franchised in 26 countries and the later in 30 countries.

\section{The problems} with a conflated notion of health

Many might think: "What is wrong with this?" Indeed, "What is wrong about an international culture of dancing which encourages youth to move?" No one can be against that. In Western culture, the issue of youth' obesity and the

3 See Rail (2006) importance of physical activity is relentlessly repeated in the media. Even the World Health Organization has declared a "global obesity epidemic" (O.M.S., 2003). I agree that we cannot be against moving. But what I am arguing here is that, in the context of neoliberal economies, this kind of TV program conflates notions of physical activity, health, beauty and happiness. To explain my point, I will touch upon how, for marginalized youth (e.g., overweight or disabled youth), drawing on these kinds of images of the dominant discourses sets them up for "failure" unless they have the strength to resist such an overwhelming message.

When looking at "So you think you can dance" or "Dancing with the stars, many of us can feel in our body the adrenalin rush it might create, the physical stimulation, the endmorphine release (the feel good hormone), the camaraderie of dancing with friends, the challenge of the virtuosity and the feeling of being alive. But would it be possible to have TV programs that create these sensations while offering less stereotypical bodies? This kind of programs produces the able body as the norm. Actually, dance, sports and physical education are central fields that influence popular perception of "normal" and "abnormal" bodies.

In August 2015, in Toronto, Canada, there were the PanAmerican Games followed by the ParaPanAmerican games for athletes with disability ${ }^{4}$. Is it thinkable that one day a TV producer will dare to present the equivalent of the ParaPanAmerican games for dancers with disability? The title could be: "So you think I

4 I chose here to keep the term person with disability used by the ParaPanAmerican games. Different terms such as disabled, handicapped, impaired all reflect different theoretical position. The term person with disability conveys the idea that the person is disabled by society as opposed to having strictly a medical condition. 
cannot dance?" Dance and disability is an expanding field. In line with what I said earlier about discourse, young disabled people are not simply victims of the dominant discourse, they can be active agents who can resist, negotiate or challenge the dominant discourse. Many examples can easily be found on the web which is a rich place to conform, negotiate or resist dominant discourses. For example, in Montreal, Luca Patuelli, (called "Lazylegz" because he was born with Arthrogryposis which limited his joint movements and affected his muscle growth) participated in the Canadian version of "You think you can dance". In Cana$\mathrm{da}$, he is known as a soloist dancer as well as dancing in a group of abled bodies. By doing so, he doesn't normalize disability but rather celebrates bodily differences. That seems to me more viable on the long run since there is no such a thing as a body that works perfectly, consistently or eternally. He succeeds to break the association of able body with happiness and disability with suffering which is entangled in the dominant societal discourse.

\section{Individual responsibility} for one's health and spread-out guilt

A conflated notion of health with able body, bodily appearance, and thin body not only promotes of one type of body in the dominant societal discourse, but also leads to an understanding of health and wellbeing in a strictly individual and consumerist way. Such TV programs dictate aspects of youth's life. On screen, we see the winners who won because of their talent and dedication. When we see the losers, they emphasise how rich the experience was and how stronger they get out of the competition. We don't see those who are backstage physically or emotionally injured. The less favorable practices of dance and performance, that find expression in and through these programs, tend to be overlooked. One of my friends, a psychologist, was employed by the Québec version of such program to make sure that the losers would not commit regrettable gesture since the vanishing of the youths' hope for glory could affect their desire for life. The TV producers did not employ her for lengthy psychological follow-up. After a few I sessions, it was the responsibility of the individual to reconstruct his or her sense of self, which bring us back to health and wellbeing discourse in which individualism is a key concept.

When interviewing the dancers who participated in our study about what health meant for them, we could detect a neoliberal discourses in which success rests on individualist actions and self-responsibility. All the artists we interviewed, without exception, considered themselves as "healthy but damaged". They did not feel that their current and past injuries conflicted with their sense of being healthy, since their construction of what it is to be healthy is "to be functional", that is, being able to respond to the choreographic demands, and that is their responsibility. In sport, that could be compared to an athlete assessing his or her health on her or his capacities to meet his or her coach demands without considering his or her chronic or acute injuries. (I'll come back to this later).

To be healthy, dancers employed various strategies to "prepare, protect, and repair" their body. Unlike athletes who often gather data about their behaviors with wearable digital devices, artists don't, but they have completely embodied the self-tracking attitude that serves them to work toward the attainment of the healthy artist able to comply to all the de- 
mands of the choreographers. When injured, dancers attributed failure to themselves, and consequently felt guilty, telling themselves they could have had "better concentration", "warmed-up or trained more", "stopped dancing earlier", "eaten better, slept more", etc. Confusion and uncertainty regarding the effectiveness of different options sometimes engendered what seems to be an endless and anxious search for ways to prevent and heal injuries, or to relieve pain and psychological distress. For example, when injured they go to see the physiotherapist who says to put ice. Then, they go to see the acupuncturist who says to put heat. In the evening they drink Chinese herbs and take conventional pain killer pills. If not successful, they think it is their fault because they didn't find the good treatment. They rarely turn to question their working environment which goes with what critics say about the dominant health and well-being discourse with its focus on individual responsibility.

Indeed critics (Crawford, 2006) maintain that this discourse is promoted to reduce the economic burden on public services and ultimately it undermines social responsibility to improve health and well-being. Although some dancers spoke out about collective issues such as low income, insecure employment and difficult work conditions (such as additional rehearsals before shows, freelancers' fatigue from holding down two jobs, inadequate studios, tight schedules aimed at minimizing touring costs, etc.), they rarely acted to counter these issues, which is not surprising in a competitive and small work environment. In this context, the likely result of complying with the dominant health discourse is that collective mobilization of dancers around health issues is restricted.

Can health advocates expect that one day grant agencies will require dance companies to deal comprehensively with aspects of occupational health and safety? That dance schools and dance organizations will seriously engage in health-promoting behavior? I hope so, because if the dance profession doesn't rise to the challenge, it may come to be regarded as irrelevant by educationists, decision makers and the public alike. In summary, a focus on individual responsibility, entangled in the health and well-being discourse affects many dimensions of the artistic practice. Artists, as other professional workers, are encouraged to engage in the self-tracking culture as part of health and worker productivity.

It is important to add that self-maintenance is not wrong per se. On the contrary, it is often satisfying, and pleasurable. It is part of our life. At the end of his life, inspired by the ancient Greece, Foucault (1994) wrote about the care of the self as a particular mode of governing the body. To him, bodily practices could aim at achieving health, wellbeing, happiness and wisdom. Unfortunately, he didn't have time to develop his latest ideas that, on first sight, don't go easily with his first writings. The problem with the idea of people engaging in the practice of selfhood in pursuit of their own interests is that neoliberalism promotes self-responsibility as part of a strategy that exerts "soft" rather than "hard" authority on people. Citizens are encouraged to voluntarily take care of themselves but the outcome of this self-care is aligned with the interest of others such as the employers, the government, or the commercial market. Assuming that individuals will act in their own sel$\mathrm{f}$-interest is problematic since individual health is subject to external forces (Crawford, 2006). That is the main point of the next section. 
Silence as a determinant of health

In Canada, the most important determinants of health are socio-economic status and employment. No need to say that dancers have a very low income, actually the lowest among the other forms of arts (R.Q.D., 2011). In terms of employment, most dancers are freelancers with full-time uncertainty. In dance, women outnumber men, which results in a competitiveness affecting these aspects of their professional life, and consequently their health. Often women have had a longer socialization process than men and they have deeply embodied "a culture of silence". Playing down the experience of pain and injuries becomes an implicit norm in women's professional dance career since expressing pain may have negative consequences. Data from our study was so convincing that we decided to present silence as a determinant of health. I want to be clear: Our data does not show that women are more injured than men, but it shows clearly that their voices is less expressed than men, which we think may have consequences on their health. Men on the other hand can express their physical injuries because their job is not as much jeopardized as it is for women. It is not to say that men don't suffer from injuries. Often they began to dance later as young adults. Because the professional milieu has a shortage of man, they are sometimes offered work before having completed the body training that a professional career requires, and they may end up with injuries.

Regardless if they were female or male dancers, all our interviewees suggested a "virtual blacklist" of choreographers to avoid if a dancer values her or his health. But no one revealed their names; the milieu is small, and secrets remain kept. It is important to add that dancer's health is inextricably linked to the other actors of the dance milieu: the choreographers, the theater directors, the journalists, the funding agencies, etc. We could use the holistic concept known as "One Health" to emphasize the complex interplay between all these components of the ecosystem. For example, some choreographers profess to be very open-minded, and deplore the fact that sometimes it is the dancers who don't want to disclose their health conditions, but other choreographers maintain an absolute aesthetic bias and want to know as little as possible about their dancers' injuries.

Whereas vocation or passion for the art form is often presented as an explanation for why artists jeopardize their health and accept difficult working conditions, we concluded that it is the dominant Western theatrical discourse, which values the supremacy of the artistic work and the surpassing of ones limits, that heads a long sequence of decisions negatively impacting artists' health. Unless all participants in the dance milieu, individually and collectively, critically address the different discourses and their embodied 'truths', changes in dancer's health and wellbeing will remain limited. 'Games of truth' are unavoidable, said Foucault (1994) but they can be played out with an ethically-based concern for oneself and for others.

Since these results come from the dance milieu, we might wonder if silence could be also viewed as a determinant of health in the context of physical education and sports. Looking at some sports such as cycling, more specifically at the famous case of Lance Armstrong but also, closer to me, the case of Geneviève Janson, a former professional bicycle racer 
from Canada, I would tend to say "yes". Geneviève won the world junior road and time trial championships in 1999. In 2000, she won the Tour de Snowy and the World Cup race in 2000. After repeating publicly that she was drug free, she admitted in 2007, that she had taken EPO. She was doping more or less continuously since she was 16 years old. She kept silence for years because of her tyrannical coach, and the pressure she felt from her doctor and sponsor. If she would have talked earlier, I guess her physical and psychological distress would have been alleviated earlier. What is interesting is that in the case of Armstrong, silence was maintained through a large conspiracy of men and in the case of Janson she was lonely in her silence. Based on these two cases, we might consider silence a determinant of health in the context of sports as it is the case in dance. Fortunately, there are different discourses, some more mainstream and other more alternatives. Movement specialists have to raise their consciousness about the competing discourses surrounding them and the effects on their health and wellbeing. An alternate discourse to the dominant Western health discourse can be seen in Somatics.

\section{Somatic education} as alternative discourse

Somatics is what people in the general public turn to when they want to slow down, when they are looking for an inward calm, when they are desperate for a break from the pace of modern life, when traditional medicine does not solve their problems, when they are fed up of the self-tracking device, etc. As said, somatics can be located under the large umbrella of mindfulness approaches and, to a certain degree, it can be associated with a marginal discourse since it contests certain aspects of entrenched neo-liberal values such as productivity, meritocracy, consumption, beauty, personal responsibility for health, etc. Although it does stress more individual responsibility than societal responsibility for health which is a characteristic of the neoliberal discourse on health. Despite a growing popularity, mindfulness approaches are not a panacea. According to Burkeman (2015), every era needs a practice it can believe as a miracle cure ( a" truth systems" wouId say Foucault) : Freudian psychoanalysis in the 1930, cognitive behavioral therapy in the 1990s, mindfulness approaches today - until research gradually reveals it to be flawed as everything else.

Somatics has increasingly developed in the dance milieu since the end of the eighties. Originating from outside the field of dance, a variety of somatic education practices such as Alexander, Body Mind Centering, or Feldenkrais, have made their way into dance institutions. These practices are all concerned with "listening to the body and responding to these sensations by consciously altering movement habits and movement choices (Eddy, 2009, p.7). According to Shusterman (1999), increasing subjective sensorial experience can help to reduce the prominence of external agencies on individual. Somatic education thus provides dancers with an alternative discourse to counteract the fantasy of an ideal body, which is so often removed from the concreteness of the sensing body. In a Foucaldian perspective, although people are socially constructed in discursive practices, they nonetheless exist as thinking, feeling subjects and social agents, capable of resistance and innovations.

Indeed, in one of our studies (Fortin, 2008), 
we found that dancers exerted individual agency by integrating the somatic discourse in three distinctive ways. For one group of dancers, the heightened perceptiveness developed through somatic education did not serve to improve their well-being; it was subverted and used to work towards what was important to them, namely, pushing the limits of their performance. What they learned from the marginal discourse of somatic education was used to lessen the negative health impacts of the dominant dance discourse they had fully appropriated and considered as inescapable and even essential to building a dance career. A second group of dancers, on one hand, manifested critical thinking in how they verbalized their reticence about certain aspects of the dominant discourse; on the other hand, they did not seem to physically experience the changes that they professed verbally. In a third group, the experience of somatic education allowed dancers to develop an internal authority. They made choices based on their intimate self-awareness, respecting the limits of their own bodies. For these dancers, the normality of pain or the excessiveness of certain artistic practices were no longer so blindly tolerated or, if so, only under certain conditions and for a limited period of time.

Markula (2004) appropriately points out that any discourse can be either emancipatory or oppressive. A somatic-based discourse is no exception, and this needs to be looked at critically. What really is important when negotiating between different discourses is knowing how they operate, each having its own "game of truth" linked to an accepted consensus about what is sound knowledge and to the accompanying hegemonic procedures that legitimatize power relations. Power, according to Foucault (1963), is not exercised through the imposition of external constraints on the person, but rather is achieved by an internalization of norms by the person.

\section{Conclusion}

In this paper, I have addressed how societal discourses surrounding us can impact our constructions of health. I have argued that our bodily practices can reinforce mainstream discourse or challenge it. I have highlighted the importance of being critical about their effects since these discourses and their associated practices intersect with how we individually and collectively construct health. I have offered examples from the dance field where there exists a conflated notion of physical activity, health, beauty and happiness. In contexts where the body is highly visible, people tend to receive and engage with dominant health and bodily discourses and practices which can lead paradoxically to unhealthy practices. Silence has been suggested as a determinant of health since not expressing one's physical limits can result in physical injuries and psychological distress. In a societal context in which body receives more and more attention, it is important that professionals in the field of art, physiotherapy, and physical education engage in critical reflexivity about values entangled in mainstream and alternative discourses. Our position in the social network of power relations enables us to facilitate change hoping that future practices will be less uncomfortable and hurtful, more equitable for everybody no matter the weight, the appearance, the age, the gender, the ableness, and so on. 
Acknowledgements:

A special thank you to Geneviève Rail, from the Simone de Beauvoir Institute, Concordia University, who helped me to think critically about health. I also thank my research assistants whose works have greatly contributed to the understanding we developed.

References:

Boxall (2014), 1 Boxall, A. (2014). 2014 is the year of health and fitness apps, says Google. Digital Trends. Available at: http://www.digitaltrends.com/mobile/google-play-store-2014most-downloaded-apps/

Burkeman, O. (2015, 17 juillet). Why does cognitive behavioral therapy suddenly seem less effective than it used to be? The Guardian Weekly .193 (6). 45.

Cederström, C., \& Spicer, A. (2015). The wellness syndrome. Cambridge, UK: Polity Press

Crawford, R. (2006). Health as a meaningful social practice. Health: An Interdisciplinary Journal for the Social Study of Health, IIIness and Medicine, 10(4). 401-420.

Eddy M. (2009). A brief history of somatic practices and dance: Historical development of the field of somatic education and its relationship to dance. Journal of dance and somatic practices, 1(1), 5-27.

Fortin, S. (dir.), (2008). Danse et santé: $D u$ corps intime au corps social. Québec : Presses de l'Université du Québec.
Foucault, M. (1963). La naissance de la clinique. Paris, Presses Universitaires de France.

Foucault, M. (1994). Les techniques de soi [5 oct. 1982]., Dits et écrits, Tome 1V, Paris : Gallimard.

Foucault M. (2004). Naissance de la biopolitique: Cours au Collège de France, 1978-1979. Paris: Gallimard.

Laws, H. (2004). Key finding of the 2 nd National inquiry into dancers' health and injury. Dance UK News, (52), 4-6.

Lupton (1995). The imperative of public health: Public health and the regulated body. London: Sage.

Lupton, D. (2014). Self-tracking cultures: towards a sociology of personal informatics (Available at: https://simplysociology.files. wordpress.com/2014/09/self-tracking-cultures-ozchi-conference-paper.pdf)

McCarty, L. P., \& Schwandt, T. A. (2000). Seductive illusions: Von Glasersfeld and Gergenon epistemology and education. Constructivism in Education: Opinions and Second Opinions on Controversial Issues. 99(1), 19 -40.

MacNeill, M., \& Rail, G. (2010). The visions, voices and moves of young "Canadians": Exploring diversity, subjectivity and cultural constructions of fitness and health. In J. Wright \& D. Macdonald (Eds.), Young people, physical activity and the everyday (pp. 175-193). London and New York: Routledge.

Rail, G., Beausoleil, N., Dallaire, H., Laberge, S. 
et Voyer, P. (2002, avril). Le rapport au corps et à la santé de travailleuses aînées. Conférence C.I.N.B.I.O.S.E., Université du Québec à Montréal, Montréal, Québec.

Rail, G. (June, 2015). The Wellbeing Imperative: On Bio-Others, Rescue Missions and Social Justice. Invited keynote presentation at the International Sociology of Sport Association annual conference, Paris, France

R.Q.D.(Regroupement québécois de la danse). (2011). Actualisation de la situation des interprètes en danse. Montréal : Regroupement québécois de la danse. (Available at: http:// www.quebecdanse.org/images/upload/files/ RQD_Actualisation_du_portrait_socioeconomique_\%20interpretes_en_danse.pdf)

Shusterman Richard, La fin de l'expérience esthétique, Pau: Presse Universitaire de Pau, 1999

Sorignet, P.-E. (2010). Danser, enquête dans les coulisses d'une vocation. Paris : Éditions la Découverte.

Rail, G. (2006). Éléments de réflexion sur la santé et la colonisation du corps féminin. In $\mathrm{C}$. Bernier et R. St-Onge (Eds.), Penser la santé des femmes dans la diversité (pp. 195-213). Sudbury, Ontario : Éditions Prise de parole, Collection Agora

O.M.S. (Organisation mondiale de la santé). 2003. Obésité: prévention et prise en charge de l'épidémie mondiale d'obésité (Série de Rapports techniques 894). Genève: O.M.S. (Available at: http:// apps.who.int/iris/bitstream/10665/42734/1/ WHO_TRS_894_fre.pdf?ua=1).
Recebido em 14/08/2016 Aprovado em 13/09/2016 